\title{
Uso de granulado de borracha em substituição parcial ao agregado miúdo na produção de tijolos ecológicos
}

\author{
Use of crumb rubber to partially replace fine \\ aggregate in the production of green bricks
}

\author{
Thayane Dias Silva ${ }^{1}$, Heber Martins de Paula ${ }^{1}$, Dyego da Silva ${ }^{1}$, \\ Igor Mazon Carvalho ${ }^{1}$, Jakson Trindade Fonte ${ }^{2}$, \\ Ruvier Rodrigues Pereira ${ }^{3}$
}

\footnotetext{
${ }^{1}$ Curso de Engenharia Civil - Universidade Federal de Goiás, Regional Catalão, CEP 75704-020, Catalão, GO e-mail: heberdepaula@ufg.br

${ }^{2}$ Curso de Engenharia de Produção - Universidade Federal de Goiás, Regional Catalão.

${ }^{3}$ PPG em Modelagem e Otimização - PPGMO - IMTec, Universidade Federal de Goiás, Regional Catalão. e-mail: thayane.dias@hotmail.com; dyegopc@hotmail.com; igor_m_carvalho@hotmail.com; jtfonte@gmail.com; ruvierrodrigues@hotmail.com
}

\begin{abstract}
RESUMO
$\mathrm{O}$ volume de resíduos sólidos produzido vem aumentando de modo desordenado e prejudicial à natureza, uma vez que não são dados a ele fins adequados. Um dos resíduos sólidos que mais vem preocupando ambientalistas, sociedade e governo são os pneus inservíveis, os quais possuem materiais em sua composição que demoram centenas de anos para se deteriorar. Sendo assim, este trabalho tem como objetivo demonstrar a viabilidade do uso de granulados de borracha de pneus inservíveis na fabricação de tijolos comuns de concreto, tornando-se uma alternativa de destinação para pneus descartados no meio ambiente. Para tanto, foram produzidos tijolos de referência (sem resíduo) e com adições de 5\%, 10\% e 20\% de granulado de borracha em substituição ao agregado miúdo, comparando-os através de ensaios de compressão simples e absorção de água nos blocos. Além disso, os tijolos produzidos foram comparados a blocos maciços cerâmicos utilizados na região de Catalão, Goiás. Houve também a caracterização química e granulométrica dos materiais utilizados para compor os tijolos ecológicos. Frente aos resultados é possível concluir que os blocos com adição do resíduo de borracha apresentaram menor densidade e peso próprio, além de possuírem maior taxa de absorção. Em relação à resistência à compressão, percebeu-se que houve uma queda de aproximadamente $76 \%$ com a adição de borracha, não havendo significativa alteração até $20 \%$ de borracha. Mesmo com estas características os tijolos atenderam às exigências das normas, o que possibilita sua indicação para alvenaria de vedação.
\end{abstract}

Palavras-chave: borracha de pneu, bloco de concreto, ensaio de absorção, resistência à compressão, granulometria.

\section{ABSTRACT}

The volume of solid waste produced is increasing disorderly and harmful to nature, since they are not given him proper purposes. One of the solid waste that is more worrying environmentalists, society and government are the scrap tires, which have materials in its composition that take hundreds of years to decay. Thus, this study aims to demonstrate the feasibility of using rubber waste tire granulates in the manufacture of common concrete bricks, becoming an alternative destination for tires discarded in the environment. For this purpose, reference bricks (no residue) and 5\%,10\% and 20\% additions of crumb rubber were produced in replacement of the small aggregate, comparing them by simple compression tests and water absorption in the blocks. In addition, the bricks produced were compared the Ceramic massive blocks used in the region of Catalão, Goiás. There was also the chemical characterization and particle size of the materials used to compose the ecological bricks. In view of the results it is possible to conclude that the blocks with addition of the rubber waste tire presented lower density and own weight, besides having a higher rate of absorption. Regarding the compressive strength, it was observed that there was a decrease of approximately $76 \%$ with the 
addition of rubber, and there was no significant change up to $20 \%$ of rubber. Even with these characteristics, the bricks have met the requirements of the standards, which allows their indication for masonry.

Keywords: tire rubber, concrete block, absorption test, compressive strength, granulometry.

\section{INTRODUÇÃO}

Um dos maiores desafios enfrentados pelo homem na atualidade é o imenso volume de resíduos sólidos gerados. O lixo torna-se problema quando não há destinação adequada e acaba ocasionando diversos transtornos socioambientais. Segundo ANDRADE [1], diariamente, toneladas de resíduos sólidos são depositadas nos lixões ou são descartados em locais inapropriados e de forma inadequada.

Segundo MOTTA [2], a falta de destino apropriado aos detritos gera a poluição das águas, solo e ar, degradação da natureza, perda de biodiversidade, danos à saúde e qualidade de vida e geração de impactos sociais e culturais, podendo tornar-se uma situação irreversível e inclusive comprometer a médio e longo prazo o próprio desenvolvimento econômico. De acordo com ANDRADE [1], um dos resíduos sólidos que mais vem preocupando ambientalistas, governo e sociedade são os pneus inservíveis.

Os aterros sanitários, principalmente dos grandes centros urbanos, estão ficando saturados devido ao crescimento do descarte de pneus. FREITAS et al. [3] afirmam que o número de pneus inservíveis em depósitos oficiais e clandestinos no Brasil ultrapassa os 100 milhões de unidades. Só em São Paulo a quantidade de pneus descartados se aproximou de 3\% do lixo urbano em 2005.

Um dos fatores que dificulta e encarece o transporte e a estocagem de pneus descartados é a capacidade de não serem compactados, devido a seu volume e sua forma. Além disso, segundo NOHARA et al. [4], os pneus possuem materiais em sua composição que podem levar cerca de 600 anos para se decompor completamente. Sendo assim, a Resolução $\mathrm{n}^{\circ}$. 258 do Conselho Nacional do Meio Ambiente (CONAMA) [5] obriga os fabricantes e importadores de pneumáticos a coletar e dar destinação correta aos mesmos.

De acordo com ROMUALDO [6], o Instituto Brasileiro do Meio Ambiente e dos Recursos Naturais (IBAMA) é o responsável por regular as formas de destinação para os pneus inúteis ou inservíveis, determinando quais processos são ambientalmente corretos. Os pneus inservíveis são mais comumente utilizados como combustível alternativo para indústrias de cimento, mas possuem outras utilidades como: fabricação de solados de sapatos, borrachas de vedação, dutos pluviais, pisos para quadras poliesportivas, pisos industriais, além de tapetes para automóveis.

De acordo com RODRIGUES e SANTOS [7], os agregados reciclados de borracha de pneu são materiais bastante promissores no ramo da construção civil devido às suas características como: leveza, elasticidade, absorção de energia e propriedades térmicas e acústicas. Segundo ROMUALDO [6], a reutilização do pneu em concretos como substituto dos agregados pode assumir um papel importante na preservação do meio ambiente, pois, além de diminuir a exploração de recursos naturais (como areia e brita), também ocasiona a redução dos resíduos sólidos acumulados na natureza.

FREITAS et al. [3] estudaram o desempenho físico-químico e mecânico de concreto de cimento Portland com borracha de estireno-butadieno reciclada de pneus e constataram, por exemplo, que a adição do resíduo de borracha em substituição à massa de areia no concreto fresco diminuiu a trabalhabilidade do concreto resultante. Notou-se também a redução na massa unitária e aumento no teor de ar aprisionado.

LING [8] analisou o comportamento de granulado de borracha de pneu em blocos de pavimentação sob os métodos de análise de resistência à compressão, à flexão e à derrapagem. Em seu estudo, ele substituiu a areia pelo resíduo de borracha, em volume, nas porcentagens de $0 \%, 10 \%, 20 \%$ e $30 \%$, e pôde observar que quanto maior a proporção de borracha no bloco, menor era sua resistência à derrapagem. Notou-se também que os blocos contendo granulado de borracha foram capazes de absorver maior quantidade de energia e a presença da borracha no concreto permitiu uma maior ductilidade do mesmo.

SADEK e EL-ATTAR [9] também desenvolveram um estudo para avaliar o efeito da borracha de pneu sobre as propriedades, dessa vez, de tijolos de solo-cimento e, consequentemente, sobre o comportamento estrutural de paredes de alvenaria sob compressão. A borracha utilizada pelos autores estava livre de aço e fibras têxteis e foi empregada em dois tamanhos para substituir os agregados graúdos e miúdos. Percebeu-se ainda que a quantidade de água absorvida pelo concreto cresceu com o aumento da quantidade de granulado de borracha.

Por fim, uma pesquisa mais recente realizada por SILVEIRA et al. [10] mostra a utilização do material em estudo (granulado de borracha) na fabricação de corpos de prova cilíndricos, aos quais foram aplicados testes de compressão axial, módulo de elasticidade, flexão simples sob carga centrada e fadiga. Os autores produziram diferentes misturas: concreto sem borracha, concreto com $10 \%$ de borracha e consumo de cimen- 
to igual ao de referência e concreto com $10 \%$ de borracha e acréscimo de $5 \%$ a $30 \%$ de cimento (até a obtenção da resistência do concreto de referência). Com isso, contaram-se que a adição de borracha no concreto, sem o acréscimo de cimento, provocou uma redução de $44 \%$ na sua resistência à compressão.

Os estudos de LING [8], SADEK e EL-ATTAR [9] e SILVEIRA et al. [10] se assemelham pelo fato de ocorrer alteração nas propriedades mecânicas dos corpos de prova de concreto à medida em que houve o acréscimo de borracha em sua composição, proporcionando uma notável redução na resistência à compressão. No entanto, de acordo com BOUDAOUD e BEDDAR [11], a substituição de partes dos agregados tradicionais por resíduos de borracha apresenta tanto vantagens econômicas quanto ecológicas.

Tomando como base a importância destes estudos, o presente trabalho teve como objetivo avaliar a empregabilidade da borracha de pneus inservíveis em substituição parcial ao agregado miúdo na produção de tijolos ecológicos, analisando-os quanto à sua resistência à compressão e à absorção de água, promovendo a reutilização de um material que é normalmente descartado na natureza de forma inadequada e prejudicial.

\section{MATERIAIS E MÉTODOS}

A proposta deste estudo partiu da substituição parcial do agregado miúdo na fabricação de blocos de concreto. Para tanto, foi adotado como material de pesquisa o granulado de borracha oriundo de pneus inservíveis, o qual foi coletado já triturado e utilizado sem nenhum tipo de tratamento. Em um primeiro momento, realizouse o ensaio de granulometria por peneiramento da areia, do cimento e do resíduo de borracha de acordo com a ABNT NBR 7217:1987 [12], a fim de se estimar as percentagens (em relação ao peso seco total) correspondentes a cada fração granulométrica dos materiais.

Com o intuito de também compreender a caracterização química da borracha, executou-se o ensaio de Análise Química por Energia Dispersiva de Raios-X (EDX). O mesmo ocorreu também para a areia e o cimento utilizados.

Depois de fabricados os tijolos ecológicos ou também chamados, neste estudo, de blocos de concreto, tomaram-se as dimensões e peso dos mesmos para determinar a densidade de cada. Foram realizados, ainda, os ensaios de Compressão Simples e de Absorção de Água de acordo com uma adaptação da ABNT NBR 8492:2012 [13]. Estes ensaios também foram aplicados a tijolos maciços cerâmicos, produzidos na região de realização do estudo, para fins comparativos.

\subsection{Materiais}

Os materiais utilizados para produzir os corpos de prova foram: cimento tipo Portland II a granel, areia natural, resíduo de borracha e água. Uma vez que o estudo consiste em empregar parcialmente o granulado de borracha no lugar da areia, fez-se uso do resíduo com a mesma granulometria de tal. Cada material foi pesado individualmente para formar os traços, os quais foram executados com base no traço utilizado na empresa parceira na fabricação de seus produtos.

Foram confeccionados quatro traços diferentes para os blocos, sendo eles T1, T2, T3 e T4, que representam, respectivamente, traço sem borracha (tratado como traço de referência utilizado para elaboração dos demais), o traço que teve substituído $5 \%$ da areia por borracha, o traço que teve $10 \%$ do seu total de areia substituída pela borracha e, por último, o traço que teve $20 \%$ da areia presente no mesmo, substituída pela borracha investigada neste estudo, os quais estão relacionados na Tabela 1. A substituição deu-se por massa e a relação água/cimento (a/c) utilizada foi 1,0 (um).

Tabela 1: Traços dos blocos de concreto.

\begin{tabular}{l|l}
\hline TRAÇO & $\begin{array}{l}\text { RELAÇ̃̃O } \\
\text { cimento:areia:borracha } \\
(\mathbf{k g})^{*}\end{array}$ \\
\hline $\mathrm{T} 1$ & $1: 9,46: 0$ \\
\hline $\mathrm{T} 2$ & $1: 8,98: 0,87$ \\
\hline $\mathrm{T} 3$ & $1: 8,5: 1,74$ \\
\hline $\mathrm{T} 4$ & $1: 7,56: 3,5$ \\
\hline *Os materiais foram substituídos em volume e converti- \\
do para massa para melhor compreensão.
\end{tabular}




\subsection{Equipamentos e métodos}

\subsubsection{Ensaio de granulometria}

Para o ensaio de Granulometria, fez-se necessário o uso da seguinte aparelhagem: balança eletrônica com resolução de $0,1 \%$ da massa da amostra de ensaio, estufa para secagem, agitador mecânico de peneiras, bandejas, pincel de cerdas macias, cronômetro, peneiras com as malhas $9,5 \mathrm{~mm} ; 4,75 \mathrm{~mm} ; 2 \mathrm{~mm} ; 1,18 \mathrm{~mm} ; 0,60$ $\mathrm{mm} ; 0,425 \mathrm{~mm} ; 0,250 \mathrm{~mm} ; 0,150 \mathrm{~mm}$ e $0,075 \mathrm{~mm}$, tampa e fundo [12].

Primeiramente, foram secadas duas amostras de resíduo de borracha em estufa com temperatura entre $105-110^{\circ} \mathrm{C}$, deixando-as esfriar à temperatura ambiente para determinar suas massas (M1 e M2). Tomou-se a amostra (M1) e reservou-se a outra (M2). A seguir, as peneiras previamente limpas foram encaixadas de modo a formar um único conjunto de peneiras, com abertura de malha em ordem decrescente do topo para a base e por último um fundo de peneiras adequado para o conjunto.

Depositou-se, então, a amostra M1 sobre a peneira superior do conjunto, que foi fechada com a tampa. $\mathrm{O}$ jogo de peneiras foi disposto sobre o agitador mecânico, preso por um dispositivo de travamento e vibrado durante cinco (5) minutos para permitir a separação e classificação prévia dos diferentes tamanhos de grão da amostra.

O material retido na primeira peneira $(9,5 \mathrm{~mm})$ foi disposto em um recipiente e pesado. $\mathrm{O}$ mesmo ocorreu para as demais peneiras e o fundo do conjunto. $\mathrm{O}$ somatório de todas as massas não diferiu mais de $0,3 \%$ da massa seca da amostra inicialmente introduzida no conjunto de peneiras, como proposto em norma.

Procedeu-se o mesmo com a amostra M2 do resíduo e com a areia. Na Figura 1 podem ser visualizadas as amostras de borracha após o ensaio de Granulometria.

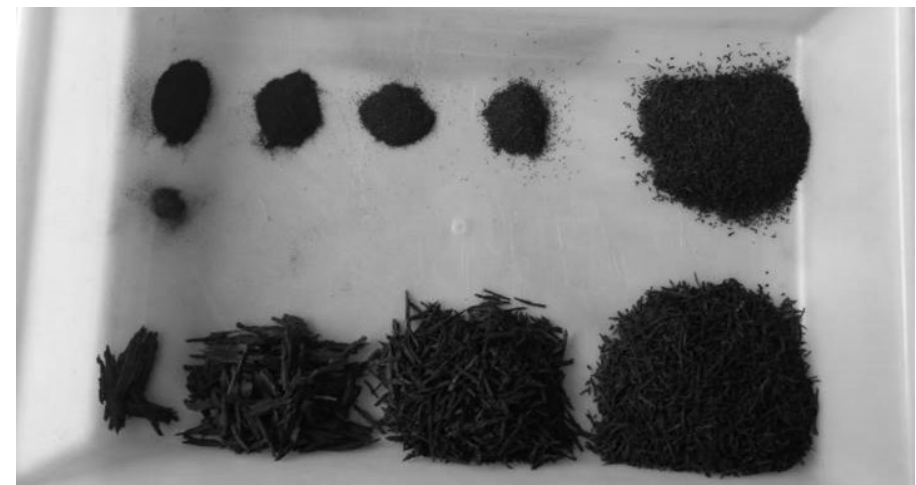

Figura 1: Amostra de borracha após peneiramento.

\subsubsection{Ensaio de energia dispersiva de raios- $X$}

Para realização do ensaio de EDX foi utilizado o Espectrômetro de fluorescência de raios X por Energia Dispersiva (EDX-7000/8000) da marca Shimadzu ${ }^{\circledR}$ e o software computacional PCEDX Navi ${ }^{\circledR}$, adequado para simplificar a espectrometria por raios X. As amostras sujeitas a este ensaio foram dispostas em recipientes pequenos chamados colimadores e acomodadas individualmente no EDX-7000/8000.

A amostra do material pode ser visualizada através do software PCEDX Navi, selecionando as condições de análise e entrada do nome da amostra na mesma tela. O armazenamento das imagens das amostras dá-se automaticamente.

$\mathrm{O}$ material ao ser colocado no Espectrômetro é irradiado por um feixe de raios $\mathrm{X}$ e os átomos da mesma geram raios característicos que são emitidos dela. Esses raios são conhecidos como raios X "fluorescentes" e possuem um comprimento de onda e energia específica, característico de cada elemento. Através da investigação dos comprimentos de onda dos raios X que é feita a análise qualitativa do material, obtida pela medição da quantidade de raios X fluorescente [14].

\subsubsection{Ensaio de compressão simples}

Para a ruptura dos corpos de prova, utilizou-se a prensa hidráulica do modelo YAW-2000, Classe 1, atendendo aos requisitos da norma ABNT NBR NM ISO 7500-1:2004 [15], referente a calibração de máquinas de ensaio estático uniaxial. Realizou-se este ensaio com base na ABNT NBR 8492:2012 [14]. Ela estabelece 
que deve-se ter como mínimo, o valor médio de 2,0 MPa e nenhum valor inferior a 1,7 MPa aos 7 dias de idade.

O tamanho da amostra para realizar os ensaios de compressão simples foi determinado de acordo com a ABNT NBR 6136:2014 [16], que recomenda um mínimo de seis (6) blocos para realização do ensaio, quando não se tem o desvio padrão da fábrica. Assim, foi adotada uma amostra de seis (6) blocos para cada um dos traços (A, B, C e D) de acordo com as idades supracitadas na metodologia. FIORITI [17] e SELUNG et al. [18] também adotaram seis (6) blocos de cada dosagem em seus estudos.

Os corpos de prova foram colocados individualmente na prensa entre duas placas lisas que aplicavam as tensões sobre o bloco. Com o rompimento do bloco, a tensão se estabilizava, ficando, assim, registrada a resistência do corpo de prova. Os resultados do ensaio foram obtidos dividindo-se, para cada bloco, a carga de ruptura pela sua área de seção transversal. A resistência média dos corpos de prova referentes a cada traço foi determinada pela média aritmética dos resultados de seis ensaios. Procedeu-se o mesmo com o lote de tijolos maciços cerâmicos.

\subsubsection{Ensaio de absorção}

De acordo com a norma ABNT NBR 8492:2012 [13] utilizou-se neste ensaio um tambor com água potável, estufa com temperatura de $(110 \pm 5)^{\circ} \mathrm{C}$, balança com resolução de $0,1 \mathrm{~g}$, escova com cerdas suaves, tela metálica com suporte e pano.

Os blocos foram submersos durante um intervalo ininterrupto de 24 horas. Após esse período, os blocos foram retirados da água, repousados sobre a tela metálica, enxugados e pesados, obtendo-se a leitura da massa de cada corpo de prova saturado. A leitura de cada corpo de prova foi realizada a cada duas horas até que não se registrasse em duas determinações sucessivas uma diferença de massa superior a $0,5 \%$ em relação ao valor anterior. Anotou-se o valor encontrado $\left(m_{2}\right)$.

Feito isso, os blocos foram colocados em estufa também durante 24 horas e posteriormente pesados individualmente, obtendo-se a leitura a cada duas horas até que não se registrasse em duas determinações sucessivas uma diferença de massa superior a $0,5 \%$ em relação ao valor anterior. Anotou-se o valor encontrado $\left(m_{l}\right)$. O limite máximo de absorção estabelecido pela norma é de $20 \%$.

Assim, para cada bloco foi calculado o valor de absorção de água a partir da Equação 1:

$$
A=\frac{m_{2}-m_{1}}{m_{1}} \cdot 100
$$

Em que:

$A$ é a Absorção de cada corpo de prova, expressa em porcentagem (\%);

$m_{l}$ é a massa do corpo de prova seco, expressa em gramas $(\mathrm{g})$;

$m_{2}$ é a massa do corpo de prova saturado, expressa em gramas (g).

\subsubsection{Fabricação dos blocos}

Para analisar a viabilidade da utilização do bloco de concreto, em substituição ao tijolinho maciço em alvenarias, o mesmo foi fabricado em moldes e com as dimensões próximas às dos tijolos maciços comercializados na região.

A ABNT NBR 7170:1983 [19] afirma que os tijolos devem possuir forma de paralelepípedo-retângulo e com dimensões nominais conforme na Tabela 2 com uma diferença de $\pm 3,0 \mathrm{~mm}$ para todas as dimensões. Todavia, os tijolos maciços comuns obtidos para comparar aos corpos de prova da pesquisa possuem dimensões médias conforme na Tabela 3, que contém também as dimensões médias dos blocos fabricados.

Tabela 2: Dimensões nominais do tijolo maciço. Adaptada [19].

\begin{tabular}{l|l|l}
\hline Comprimento $(\mathbf{m m})$ & Largura $(\mathbf{m m})$ & Altura $(\mathbf{m m})$ \\
\hline 190 & 90 & 57 \\
\hline 190 & 90 & 90 \\
\hline
\end{tabular}


Tabela 3: Dimensões nominais médias dos tijolos maciços e dos blocos fabricados.

\begin{tabular}{l|l|l|l}
\cline { 2 - 4 } & Comprimento $(\mathbf{m m})$ & Largura $(\mathbf{m m})$ & Altura $(\mathbf{m m})$ \\
\hline Tijolo maciço & 195 & 87 & 42 \\
\hline Bloco fabricado & 194 & 95 & 55 \\
\hline
\end{tabular}

Para a fabricação dos corpos de provas, utilizou-se betoneira, balança, mesa vibratória e fôrmas retangulares untadas com óleo na sua parte interna para facilitar a desforma dos blocos.

Para compor os traços dos blocos, pesaram-se os materiais individualmente e, a seguir, eles foram colocados na betoneira para serem misturados juntamente com água. Após certo tempo de mistura, a massa foi disposta nas formas e vibrada pela mesa vibratória para sua melhor acomodação ou adensamento. Com cinco dias de cura os blocos foram desenformados. Foram fabricados 22 blocos para cada traço com adição de borracha (T2, T3, T4) mais 22 para o traço de referência (T1), contabilizando ao todo 88 blocos de concreto.

Utilizou-se paquímetro para medir as dimensões dos blocos e uma balança para obter sua massa. A densidade de cada corpo de prova foi estimada dividindo-se sua massa pelo seu volume.

\section{RESULTADOS E DISCUSSÕES}

\subsection{Análise Química}

A caracterização química dos materiais aplicados ajuda a compreender quais elementos os compõe. Assim, a partir do ensaio de EDX, foram obtidas as caracterizações químicas do cimento, da borracha e da areia, as quais estão dispostas na Tabela 4.

Tabela 4: Caracterização química do cimento, da areia e do resíduo de borracha.

\begin{tabular}{l|l|l|l}
\hline ELEMENTO & CIMENTO (\%) & AREIA (\%) & BORRACHA (\%) \\
\hline $\mathbf{C a}$ & 82,235 & 1,036 & 1,409 \\
\hline $\mathbf{S i}$ & 8,807 & 69,514 & 12,819 \\
\hline $\mathbf{A l}$ & 0,0 & 9,840 & 0,0 \\
\hline $\mathbf{F e}$ & 4,986 & 6,851 & 1,345 \\
\hline $\mathbf{K}$ & 0,569 & 10,743 & 1,226 \\
\hline $\mathbf{T i}$ & 0,414 & 1,463 & 0,186 \\
\hline $\mathbf{S}$ & 1,948 & 0,0 & 16,008 \\
\hline $\mathbf{S r}$ & 0,730 & 0,039 & 0,0 \\
\hline $\mathbf{M n}$ & 0,093 & 0,351 & 0,0 \\
\hline $\mathbf{Z n}$ & 0,110 & 0,062 & 66,851 \\
\hline $\mathbf{C u}$ & 0,036 & 0,051 & 0,155 \\
\hline $\mathbf{C r}$ & 0,033 & 0,0 & 0,0 \\
\hline $\mathbf{Z r}$ & 0,0 & 0,0 & 0,0 \\
\hline $\mathbf{V}$ & 0,035 & 0,0 & 0,0 \\
\hline $\mathbf{R b}$ & 0,0 & 0,050 & 0,0 \\
\hline $\mathbf{N i}$ & 0,004 & 0,0 & 0,0 \\
\hline
\end{tabular}

Para a fabricação dos pneus há a presença de óxido de zinco como ativador de vulcanização em compostos de borracha, o que justifica (Tabela 4) a maior concentração desse metal na investigação do EDX. Ao comparar a composição química do granulado de borracha, com o cimento e o agregado miúdo, foi possível perceber que não há semelhanças significativas que possam justificar a substituição da areia pela borracha. Para o cimento a maior concentração foi de cálcio $(\mathrm{Ca})$, presente nos compostos de óxidos e carbonatos de cálcio, responsáveis pela formação dos cristais de $\mathrm{C}_{3} \mathrm{~S}$, por exemplo, durante o processo de hidratação do cimento. 


\subsection{Composição granulométrica}

Os ensaios de granulometria, tanto da areia quanto do resíduo de borracha, apresentaram semelhanças. Em ambos os casos, ficou a maior parcela do material retida nas peneiras com abertura de 2,00 e 0,85 mm. As curvas granulométricas da areia e do granulado de borracha podem ser observadas na Figura 2.

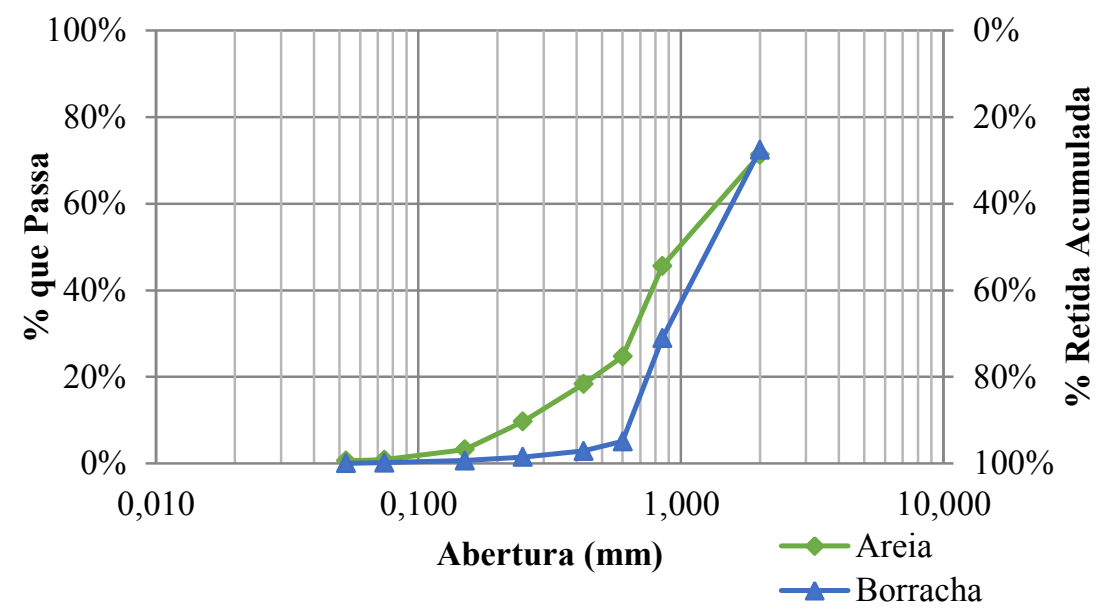

Figura 2: Curvas granulométricas da borracha e da areia.

As características dos materiais, neste caso a granulometria, direcionaram a substituição do agregado miúdo (areia) pelo granulado de borracha. Essa substituição foi realizada em volume e convertida em massa para melhor compreensão dos resultados.

Conforme a ABNT NBR 7217:1987 [12], o módulo de finura é dado pela soma das porcentagens retidas acumuladas em massa de um agregado, nas peneiras da série normal, dividida por 100. Assim, o módulo de finura do resíduo de borracha e da areia é 1,12 e 1,74, respectivamente.

\subsection{Absorção de água e vazios}

De acordo com a ABNT NBR 8492:2012 [13], realizou-se o ensaio de absorção nos blocos de concreto fabricados e obtiveram-se os valores resultantes, tanto individuais quanto a média destes, os quais estão apresentados na Tabela 5 .

Tabela 5: Resultados obtidos para o ensaio de absorção de água.

\begin{tabular}{|c|c|c|c|c|}
\hline \multirow[b]{2}{*}{ Traço } & \multirow[b]{2}{*}{ Bloco } & \multicolumn{3}{|c|}{ Absorção de Água (\%) } \\
\hline & & Individual & Média & \begin{tabular}{|l|} 
Desvio \\
Padrão
\end{tabular} \\
\hline \multirow{4}{*}{$\mathrm{T} 1$} & 1 & 6,75 & \multirow{4}{*}{6,71} & \multirow{4}{*}{0,14} \\
\hline & 2 & 6,84 & & \\
\hline & 3 & 6,75 & & \\
\hline & 4 & 6,51 & & \\
\hline \multirow{4}{*}{$\mathrm{T} 2$} & 1 & 7,10 & \multirow{4}{*}{7,25} & \multirow{4}{*}{0,19} \\
\hline & 2 & 7,08 & & \\
\hline & 3 & 7,36 & & \\
\hline & 4 & 7,46 & & \\
\hline \multirow{4}{*}{$\mathrm{T} 3$} & 1 & 8,31 & \multirow{4}{*}{8,95} & \multirow{4}{*}{0,60} \\
\hline & 2 & 8,57 & & \\
\hline & 3 & 9,39 & & \\
\hline & 4 & 9,54 & & \\
\hline $\mathrm{T} 4$ & 1 & 9,56 & 9,37 & 0,50 \\
\hline
\end{tabular}




\begin{tabular}{l|l|l|l|l}
\hline 2 & 9,10 & \multirow{4}{*}{} & \\
\cline { 1 - 2 } 3 & 8,85 & & \\
\cline { 2 - 3 } & 4 & 9,97 & & \\
\hline
\end{tabular}

A partir dos dados referentes à absorção de água, observa-se que os mesmos não ultrapassaram o limite máximo proposto pela norma ABNT NBR 8492:2012 [13] que se configura em 20\%, tanto na análise individual dos corpos de prova, quanto na análise da média obtida de absorção. Verifica-se que, para o traço de referência (T1), mesmo aquém do proposto pela norma, obteve-se o valor médio (de 6,71\%) mais baixo.

Essa maior absorção de água por parte dos blocos com maior porção de borracha pode ser atribuída à fraca ligação entre o resíduo granulado e a matriz de cimento, permitindo a entrada do líquido através dos vazios na interface entre a borracha e a pasta de cimento [20], como pode ser observado na Figura 3. O contrário ocorre com o quartzo presente na areia, podendo ser notada a maior aderência entre o mineral e a pasta cimentícia.

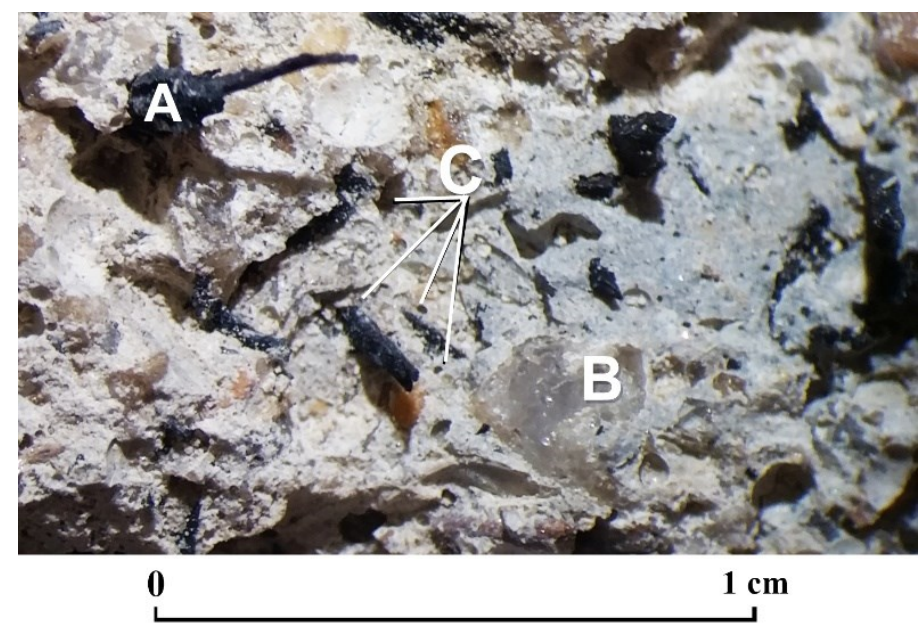

Figura 3: Aderência entre borracha e matriz de cimento. (A) Borracha; (B) Quartzo; (C) Vazios.

SADEK e EL-ATTAR [9] investigaram a absorção de água em tijolos de solo-cimento contendo borracha grossa e borracha fina, com o aumento ou não do teor de cimento. Constatou-se que para os tijolos contendo borracha grossa houve um aumento sistemático na absorção de água com o aumento do teor de granulado grosso, independente do teor de cimento. Em contrapartida, foi certificado que tijolos com até $20 \%$ de borracha fina tiveram baixa absorção de água, pois a areia neste caso pode preencher os vazios ocasionados pelo granulado fino. Já os tijolos com porção de borracha fina maior que $20 \%$ demonstraram um aumento considerável de absorção de água na medida em que se aumentava a quantidade de resíduo fino.

Em comparação ao tijolo maciço, que absorveram em média 19,4\% de água, os resultados de absorção dos blocos de concreto apresentaram-se satisfatórios com valores entre 6,7 a 9,4. Comparando as médias, adotando o teste de SCOTT-KNOTT [21], foi possível observar claramente a divisão em dois grupos, sendo o grupo 1 com os blocos T1 (referência) e T2 (5\% de borracha); e o grupo 2 com os blocos T3 (10\% de borracha) e T4 (20\% de borracha) que apresentaram igualdade estatística nas médias das absorções. Assim, a utilização de blocos de concreto com adição de borracha em substituição ao tijolo maciço comum torna-se uma alternativa viável devido à sua menor absorção de água e, consequentemente, haverá menor transporte de elementos contaminantes que possam comprometer os elementos estruturais e não-estruturais.

Os vazios, além de ocasionar a absorção de água, também determinam a densidade dos blocos. Quanto mais vazios existirem no corpo de prova, menor será sua densidade. Neste estudo, o granulado de borracha, por ser leve, também ajudou a diminuir a densidade do bloco que o continha, além de aumentar os vazios. As densidades médias dos blocos em estudo estão apresentadas na Tabela 6, de acordo com cada traço. 
Tabela 6: Densidades médias de acordo com os traços.

\begin{tabular}{l|l|l|l}
\hline TRAÇO & $\begin{array}{l}\text { VOLUME } \\
\left(\mathbf{( m}^{3}\right)\end{array}$ & $\begin{array}{l}\text { MASSA } \\
(\mathbf{k g})\end{array}$ & $\begin{array}{l}\text { DENSIDADE } \\
\left(\mathbf{k g} / \mathbf{c m}^{\mathbf{3}}\right)\end{array}$ \\
\hline $\mathrm{T} 1$ & 1,013 & 2,270 & 2,240 \\
\hline $\mathrm{T} 2$ & 1,003 & 2,114 & 2,109 \\
\hline $\mathrm{T} 3$ & 0,984 & 1,961 & 1,993 \\
\hline $\mathrm{T} 4$ & 1,000 & 1,916 & 1,916 \\
\hline
\end{tabular}

A partir dos valores da Tabela 6 nota-se que a densidade diminui com o aumento do teor de granulado de borracha no bloco, logo essa diminuição não foi tão significativa.

\subsection{Ensaio de Compressão Simples}

No decorrer do teste de compressão simples foi notado que os blocos com traço T1 (sem adição de borracha), ao se romperem, se esfacelaram especialmente nas bordas, como pode ser visto na Figura 4, enquanto os blocos contendo granulado de borracha romperam-se sem apresentar esfacelamento. SADEK e EL-ATTAR [9] perceberam o mesmo em seu estudo, e atribuíram essa característica à presença da borracha, a qual possui flexibilidade e capacidade de alongar e girar em torno dos seus eixos.

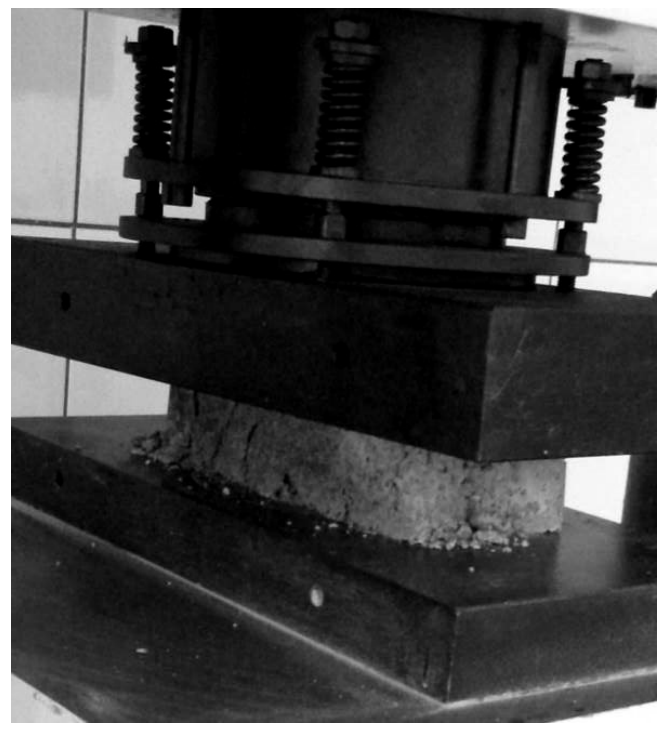

Figura 4: Rompimento de bloco com traço T1.

Para simplificar a análise dos resultados do teste de Compressão Simples, utilizou-se o Método de comparação de médias de SCOTT- KNOTT [21] para organizar os resultados sem que haja sobreposição dos mesmos, uma vez que o experimento possui grande quantidade de itens analisados [22]. A Tabela 7 apresenta as médias dos resultados obtidos e comparados para os blocos com 7, 14 e 28 dias de acordo com cada traço e representadas graficamente pela Figura 5.

Tabela 7: Resultado médio e desvio padrão do ensaio de compressão simples para os blocos de cada traço nas idades 7, 14 e 28 dias (Método Scott-Knott).

\begin{tabular}{|c|c|c|c|c|c|}
\hline $\mathbf{C P}$ & $\begin{array}{l}\text { TIJOLO } \\
\text { MACIÇO }\end{array}$ & T1 & $\mathbf{T 2}$ & $\mathbf{T 3}$ & T4 \\
\hline 7 dias & $1,65( \pm 0,47 *) \mathrm{Aa}^{* *}$ & $21,07( \pm 2,69) \mathrm{Bc}$ & $7,53( \pm 1,18) \mathrm{Cb}$ & $6,99( \pm 0,74) \mathrm{Cb}$ & $5,77( \pm 0,57) \mathrm{Cb}$ \\
\hline 14 dias & $1,65( \pm 0,47) \mathrm{Aa}$ & $28,34( \pm 3,32) \mathrm{Cc}$ & $9,26( \pm 1,04) \mathrm{Cb}$ & $8,25( \pm 1,42) \mathrm{Cb}$ & $6,65( \pm 1,06) \mathrm{Cb}$ \\
\hline 28 dias & $1,65( \pm 0,47) \mathrm{Aa}$ & $24,93( \pm 2,85) \mathrm{BCc}$ & $9,42( \pm 2,04) \mathrm{Cb}$ & $7,40( \pm 1,36) \mathrm{Cb}$ & $8,27( \pm 1,18) \mathrm{Db}$ \\
\hline
\end{tabular}




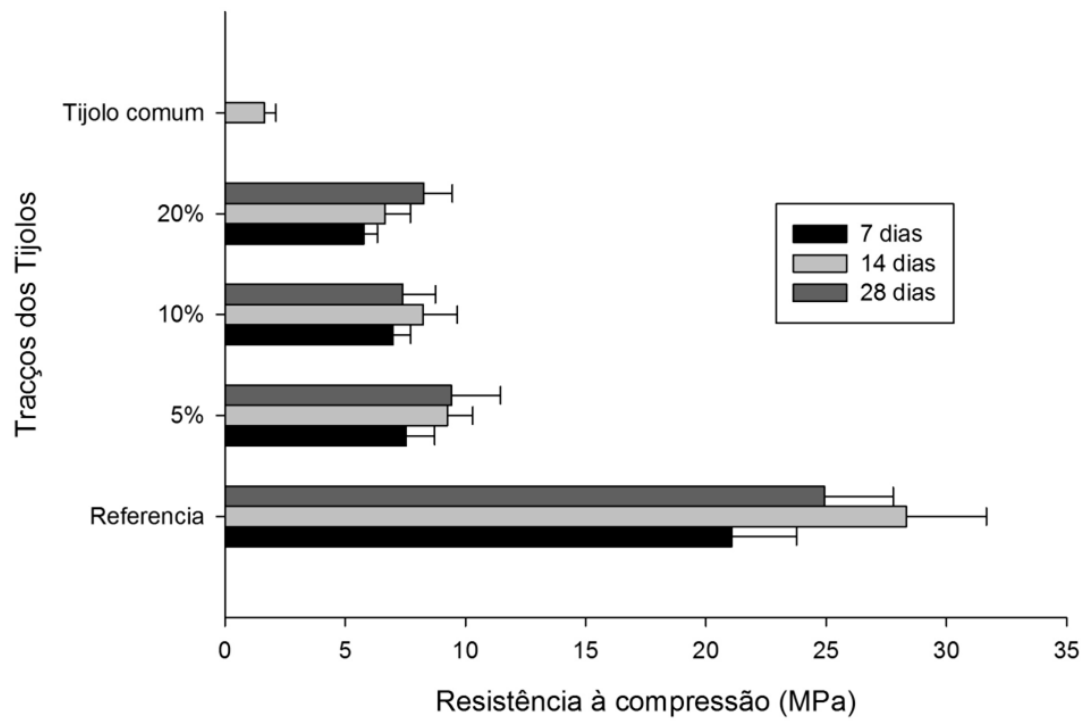

Figura 5: Resultado gráfico do ensaio de compressão simples.

Observou-se que com a substituição de areia por resíduo de borracha houve uma significativa perda de resistência à compressão, como pode ser observado na Figura 5. Dentre os blocos com cura de 7 e 14 dias, o traço que apresentou maior perda de resistência foi o T4 (possui 20\% de agregado substituído por borracha) com uma queda de $72,6 \%$ e $76,5 \%$, respectivamente. Já nos blocos com cura de 28 dias, o traço que teve pior desempenho quanto à compressão foi o T3 (10\% de borracha substituindo a areia), com uma perda de resistência de 73,5\%. Vale ressaltar também o comportamento dos blocos de referência e aqueles com $10 \%$ de adição de borracha, em que apresentaram resistência aos 28 dias inferior aos de 14 dias. Esta perda de resistência ao longo da idade de alguns traços também foi verificada no estudo de KOUL et al. [23], porém não foi realizado nenhuma verificação ou discussão acerca desse comportamento. Isso aponta uma importante lacuna para novos estudos que abordem a microestrutura dos blocos.

As médias das perdas de resistência convergem para um resultado comum conforme apresentado na Tabela 7, ou seja, estatisticamente, todos estiveram no mesmo patamar de resistência. Em relação ao tijolo cerâmico comum, tem-se que eles tiveram uma resistência média de 1,65 MPa, significativamente inferior aos resultados obtidos para os tijolos moldados neste estudo.

A redução da resistência em blocos de concreto com o acréscimo de borracha também foi observada em outros trabalhos. SILVEIRA et al. [10] analisaram blocos produzidos com concreto convencional (areia, brita, cimento e água) e concreto modificado com $10 \%$ de borracha, considerando também aumento de 5\% a $30 \%$ no consumo de cimento. Observou-se que a adição de borracha no concreto, sem o acréscimo de cimento, provocou uma redução de $44 \%$ na sua resistência à compressão.

LING [8] estudou blocos de concreto para pavimentação com adição de resíduo de pneus (granulado de borracha) em substituição à areia, em volume, nas porções de $0 \%, 10 \%, 20 \%$ e $30 \%$. Dois métodos de compactação para fabricar os blocos foram utilizados: método manual e mecânico. Foram analisados blocos com $20 \%$ de adição de borracha com módulo de finura de 4,74 e constatou-se que houve uma queda na resistência à compressão de 50\% e 52,6\% para os tijolos fabricados com método mecânico e manual, respectivamente. Ainda foi possível observar, neste estudo, que a resistência à compressão variou, em relação aos métodos de fabricação (manual ou mecânico), de 1,92 a 3,48 vezes dependendo da porcentagem de borracha utilizada. Quanto maior o teor de borracha, menor o valor de resistência à compressão relativa.

SADEK e EL-ATTAR [9] também analisaram blocos de concreto com adição de borracha e constataram que houve uma sistemática redução na resistência à compressão de acordo com o aumento do teor de granulado de borracha, independentemente do teor de cimento ou do tamanho do resíduo. Como foram produzidos blocos com granulados de borracha de tamanhos diferentes (fino e grosso), os autores perceberam que os tijolos contendo borracha fina apresentaram maior resistência à compressão do que os que continham borracha grossa.

Nota-se que, mesmo sendo diferentes as composições dos blocos dos estudos citados e da presente pesquisa, em todos constatou-se uma significativa queda na resistência à compressão com o acréscimo de 
granulado de borracha, independentemente de suas dimensões. Segundo NEHDI e KHAN [24], SKRIPKIUNAS et al. [25] e SODUPE-ORTEGA et al. [26], isso ocorre devido:

I. À menor quantidade de carga sólida no material após substituir o agregado convencional rígido e denso, pelo resíduo de borracha flexível e menos denso;

II. Ao ar retido na superfície da borracha, consequência da repulsão da água pelo resíduo durante o processo de mistura, provocando assim uma queda na resistência à compressão;

III. À incompatibilidade elástica entre as partículas de borracha e a matriz de cimento, produzindo vazios na interface matriz de cimento/borracha.

Os resultados das resistências à compressão dos tijolos estudados atingiram valores acima do exigido pela ABNT NBR 8492:2012 [13]. Vale destacar que, nas amostras com 5\%, 10\% e 20\% de borracha, os resultados foram semelhantes estatisticamente, segundo análise de comparação de médias, o que indica uma possibilidade de substituição de uma parcela ainda maior de borracha no traço dos tijolos.

\section{CONCLUSÕES}

Os blocos com borracha em sua composição apresentaram menor densidade devido a borracha ser mais leve que a areia e também aos vazios decorrentes da fraca ligação entre a matriz de concreto e o granulado de borracha, apresentando assim menor peso próprio.

Também devido aos vazios, os blocos com borracha apresentaram maior taxa de absorção de água à medida que se aumentava a quantidade de resíduo. Assim, os corpos de prova com $20 \%$ de areia substituída por borracha absorveram mais água que os demais, porém, não mais que os tijolos cerâmicos maciços da região de Catalão, Goiás. Contudo, em todos os casos os tijolos atenderam as exigências da ABNT NBR 8492:2012 [13].

À medida que se aumenta a quantidade de granulado de borracha, ocorre uma queda significativa na resistência à compressão em relação à do tijolo de referência (T1), porém ainda apresentam melhor desempenho que o tijolo cerâmico maciço. Cabe destacar que estatisticamente os resultados para os tijolos com adição de borracha foram iguais, o que significa que se pode adotar até $20 \%$ de borracha em substituição ao agregado sem que se tenha perda relevante de resistência.

Pode-se concluir que os blocos com adição de borracha são uma alternativa viável tecnicamente e com um grande potencial sustentável, reduzindo a exploração dos recursos naturais e incorporando um resíduo que seria disperso no meio ambiente.

\section{AGRADECIMENTOS}

Às empresas Brasmix e Vipal, que cederam materiais, e à GS Pré-Moldados por fornecer equipamentos, local e mão-de-obra para a fabricação dos tijolos de concreto. Aos responsáveis pelos Laboratórios dos cursos de Geografia, Química e Engenharia Civil por auxiliarem na execução dos ensaios desenvolvidos neste projeto e a Fundação de Amparo à Pesquisa do Estado de Goiás - FAPEG.

\section{BIBLIOGRAFIA}

[1] ANDRADE, H.S. Pneus inservíveis: alternativas possiveis de reutilização. Monografia, Universidade de Santa Catarina, Florianópolis, 2007.

[2] MOTTA, F. G. "A cadeia de destinação dos pneus inservíveis - o papel da regulação e do desenvolvimento tecnológico", Ambiente \& Sociedade, Campinas, v. XI, n. 1, pp.167-184, Jun. 2008.

[3] FREITAS, C., PORTELLA, K.F., JOUKOSKI, A., et al. "Desempenho físico-químico e mecânico de concreto de cimento Portland com borracha de estireno-butadieno reciclada de pneus", Química Nova, Curitiba, v. 32, n. 4, pp. 913-918, Jan. 2009.

[4] NOHARA, J. J., ACEVEDO, C.R., PIRES, B.C.C., et al. "GS-40 - resíduos sólidos: passivo ambiental e reciclagem de pneus", Thesis, São Paulo, v. 3, n. 1, pp. 21-57, 2005.

[5] BRASIL. Ministério do Meio Ambiente. Resolução no 258, de 26 de agosto de 1999. Determina que as empresas fabricantes e as importadoras de pneumáticos ficam obrigadas a coletar e dar destinação final ambientalmente adequadas aos pneus inservíveis.

[6] ROMUALDO, A. C. A., SANTOS, D.E., CASTRO, L.M., et al. "Pneus inservíveis como agregados na composição de concreto para calçadas de borracha", In: 3rd International workshop advances in cleaner production, São Paulo, Brasil, 2011. 
[7] RODRIGUES, J. P. C., SANTOS, C. C. "Resistência à compressão a altas temperaturas do betão com agregados reciclados de borracha de pneu", In: Congresso Ibero Latino Americano sobre Segurança contra Incêndio, pp. 409-418, Coimbra, 2013.

[8] LING, T. "Effects of compaction method and rubber content on the properties of concrete paving blocks", Construction And Building Materials, Hong Kong, v. 28, n. 1, pp. 164-175, Mar. 2012.

[9] SADEK, D. M., EL-ATTAR, M. M. "Structural behavior of rubberized masonry walls", Journal of Cleaner Production, Cairo, v. 89, pp. 174-186, Fev. 2015.

[10] SILVEIRA, P. M. et al. "Estudo do comportamento mecânico do concreto com borracha de pneu", Matéria, São Paulo, v. 21, n. 2, pp. 416-428, Jun. 2016.

[11] BOUDAOUD, Z., BEDDAR, M. "Effects of Recycled Tires Rubber Aggregates on the Characteristics of Cement Concrete", Open Journal of Civil Engineering, Argélia, v. 2 No. 4, 2012, pp. 193-197.

[12] ASSOCIAÇÃO BRASILEIRA DE NORMAS TÉCNICAS. NBR 7217: Agregados - Determinação da composição granulométrica. 3p. Rio de Janeiro, 1987.

[13] ASSOCIAÇÃO BRASILEIRA DE NORMAS TÉCNICAS. NBR 8492: Tijolo maciço de solocimentoDeterminação da resistência á compressão e da absorção de água: Referências: Elaboração. 4p. Rio de Janeiro, 2012.

[14] Shimadzu, SHIMADZU EXCELLENCE IN SCIENCE, http://www.shimadzu.com.br/analitica/index.shtml. Acessado em julho de 2016.

[15] ASSOCIAÇÃO BRASILEIRA DE NORMAS TECNICAS. NBR NM ISO 7500-1(2004): Materiais metálicos - Calibração de máquinas de ensaio estático uniaxial. Parte 1: Máquinas de ensaio de tração/compressão - Calibração do sistema de medição da força. 27p. Rio de Janeiro, 2004.

[16] ASSOCIAÇÃO BRASILEIRA DE NORMAS TÉCNICAS. NBR 6136: Blocos vazados de concreto simples para alvenaria - Requisitos. 10p. Rio de Janeiro, 2014.

[17] FIORITI, C.F., AKASAKI, J.R. "Fabricação de blocos estruturais de concreto com resíduos de borracha de pneus", Holos Environment, v.4 n.2, pp. 145, 2004.

[18] SELUNG, C.S., MENEGOTTO, M.L., MENEGOTTO, A.G.F., et al., "Avaliação de blocos de concreto para alvenaria com adição de resíduos de borracha de pneus", Holos Environment, v. 13 n.2, p 212-223, 2013.

[19] ASSOCIAÇÃO BRASILEIRA DE NORMAS TÉCNICAS. NBR 7170: Tijolo maciço cerâmico para alvenaria. 4p. Rio de Janeiro, 1983.

[20] SHTAYEH, S. Utilization of Waste Tires in the Production of Non-structural Portland Cement Concrete, Tese de M.Sc., Faculty of Graduate Studies, Al-Najah National University, Nablus, Palestine, 2007.

[21] SCOTT, A. J., KNOTT, M. "A cluster analysis method for grouping means in the analysis of variance". Biometrics, v.30, n.3, pp. 507-512, 1974.

[22] CANTERI, M.G., ALTHAUS, R.A., VIRGENS FILHO, J.S., et al., "SASM-AGRI-Sistema para análise e separação de médias em experimentos agrícolas pelos métodos Scott-Knott, Tukey e Duncan", Revista Brasileira de Agrocomputação, Ponta Grossa-PR, v.1, n.2, p.18-24, Dez. 2001.

[23] KOU, S. et al., "Feasibility study of using recycled fresh concrete waste as coarse aggregates in concrete", Construction And Building Materials, v. 28, n. 1, pp.549-556, Mar. 2012.

[24] NEHDI, M., KHAN, A. "Cementitious Composites Containing Recycled Tire Rubber: An Overview of Engineering Properties and Potential Applications", Cement, Concrete, and Aggregates, CCAGDP, v. 23, n. 1, pp. 3-10, 2001.

[25] SKRIPKIUNAS, U. G., GRINYS, A., CERNIUS, B. "Deformation properties of concrete with rubber waste additives", Materials Science, v. 13, n. 3, 2007.

[26] SODUPE-ORTEGA, E., SANZ-GARCÍA, A., FRAILE-GARCÍA, E., et al. "Increasing of thermal insulation and sustainability in hollow concrete blocks using recycled materials", In: 16th International Congress on Project Engineering, Valencia, 11 e 13 July. 